\title{
O QUOTIDIANO DO HOSPITAL OU "PARA UMA ORDEM CONFUSIONAL"
}

\author{
THE QUOTIDIAN OF A HOSPITAL OR 'FOR A CONFUSIONAL ORDER' \\ EL COTIDIANO DEL hOSPITAL O "PARA UNA ORDEN CONFUSIONAL" 1
}

\author{
Roseney Bellato 2 \\ Emilia Campos de Carvalho ${ }^{3}$
}

RESUMO: Este artigo pretende contribuir para a reflexão sobre a "dinâmica conflitual" que existe entre o normatizado, o instituído e o trabalho quotidiano do grupo de enfermagem no hospital. Procuramos enfatizar dessa forma a necessidade de se compreender a dimensão humana presente nesse "ambiente confusional", revelada através da diversidade de interesses, sentimentos e as contradições que não se prestam à homogeneização pretendida.

UNITERMOS: Trabalho no hospital - Grupo de enfermagem - Enfermeira.

\begin{abstract}
This article intends to contribute for a reflection on 'conflictual dynamics' that exists among the normatized, the instituted and the quotidian work of the nursing team at the hospital. We have tried to emphasise the need of comprehending the human dimension at a 'confusional environment', revealed through the diversity of interests, feelings and contradictions that make no good to the intended homogenisation.
\end{abstract}

KEYWORDS: Work at the hospital - Nursing team - Nurse

RESUMEN: Este artículo pretende contribuir para la reflexión sobre la "Dinámica conflictual" que existe entre lo normatizado, lo instituído y el trabajo cotidiano del grupo de enfermería en el hospital. Buscamos enfatizar de esta forma la necesidad de comprenderse la dimensión humana presente en ese "ambiente confusional" revelada por medio de la variedad de intereses, sentimientos y las contradicciones que no se prestan a la homogenización pretendida.

UNITÉRMINOS: Trabajo en el hospital - Grupo de enfermería - Enfermera.

${ }^{1}$ Artigo baseado na Dissertaçăo de Mestrado defendida em 1996, junto ao Programa de Mestrado em Enfermagem Fundamental da EERP/USP, intitulado "O mito do instituído e a banalidade do vivido no quotidiano de um Hospital Universitário"

2 Professora Assistente da Faculdade de Enfermagem e Nutriçăo da Universidade Federal de Mato Grosso e aluna do Doutorado em Enfermagem Fundamental da EERPIUSP.

3 Professora Titular, Orientadora do Programa de Doutorado em Enfermagem Fundamental da EERP/USP.

R. Bras. Enferm. Brasilia, v. 51, n. 1, p. 7-18, jan./mar., 1998 


\section{O HOSPITAL - UMA HISTÓRIA}

O hospital, ao longo de sua história, apresentou consideráveis variações em sua função. Instituição bastante antiga, anterior à era cristã, sofreu influência de vários fatores na sua evolução que the conferiram características diferenciadas em cada época. Segundo nos coloca Trevizan (1986), tais fatores foram, principalmente, o sobrenatural, a guerra, a caridade, a ciência e a situação econômico-financeira das populações, sendo que tal influência se deu de maneira distinta ao longo do tempo.

Porém, o fator caritativo-religioso foi bastante forte durante grande parte da história da instituição hospitalar e, como ressalta Foucault (1993),

"o personagem ideal do hospital, até o século XVIII, não é o doente que é preciso curar, mas o pobre que está morrendo. É alguém que deve ser assistido material e espiritualmente...Dizia-se correntemente, nesta época, que o hospital é um morredouro, um lugar onde morrer. E o pessoal hospitalar não era fundamentalmente destinado a realizar a cura do doente, mas a conseguir sua própria salvação. Era um pessoal caritativo-religioso ou leigo... Assegurava-se, portanto, a salvação da alma do pobre no momento da morte e a salvação do pessoal hospitalar que cuidava dos pobres."

Mas, se houve a predominância desse caráter caritativo-religioso durante séculos, o hospital serviu também para o afastamento dos pobres, loucos e outros indesejáveis ao convívio social, o que o tornava

"uma espécie de instrumento misto de exclusão, assistência e transformação espiritual, em que a função médica não aparece. "(Foucault, 1993: 102)

Somente a partir de meados do século XIX é que o hospital começa a ganhar nova feição advinda, principalmente, do desenvolvimento na área da microbiologia com os estudos de Pasteur e Lister. Cabe mencionar, também, a importante contribuição de Florence Nightingale para a organização do hospital, o que propiciou significativa diminuição nas altas taxas de mortalidade hospitalar da época. Sua influência se fez sentir desde a organização dos serviços de enfermagem, lavanderia, cozinha, limpeza, etc, até na própria coordenaçăo e administração do hospital que, aos poucos, vai se transformando em uma instituiçăo destinada à cura de doenças, dentro de um crescente processo de medicalização.

$O$ final do século $X I X$ e início do século $X X$ trazem consigo os fortes ventos da revolução científica, que adentram as portas do hospital de duas maneiras, conforme nos coloca Trevizan (1986). A primeira é traduzida pelo conhecimento técnico-científico propriamente dito, que acarretou os novos conhecimentos da bacteriologia e da assepsia, o uso de aparelhos para o diagnóstico, bem como 
novas drogas para o tratamento, enriquecendo o arsenal médico e dando maior credibilidade à instituição hospitalar como local destinado à cura de doenças.

A segunda influência da revolução científica se deu como consequeencia direta da primeira posto que, com a melhoria das condições de atendimento por parte do hospital, este passou a ser buscado com maior intensidade pela população, havendo, portanto, um grande incremento em suas atividades. Conseqüentemente, esse incremento trouxe a necessidade de pessoal adicional para desempenhar as novas funçőes que se criaram. Com isso, surgem situações inusitadas que precisavam ser enfrentadas pelos dirigentes da instituição, decorrentes do aumento no número do pessoal aí atuante e na demanda das atividades que estes desempenhavam.

\section{HOSPITAL - "EMPRESA DE SAÚDE"}

Contemporâneo a esses acontecimentos, se desenvolve nas indústrias estudo de base cientifica para a organização do trabalho visto que, com a revolução industrial,

"as oficinas são substituídas pelas fábricas, os homens pelas máquinas. Há o aumento da produção com baixa dos preços e o consequente aumento do consumo. Nas fábricas começa a demanda de pessoal para atender a essa nova modalidade de produção." (Kurcgant, 1991)

É dentro dessa ótica que surge a Teoria Científica da Administração, cujo maior representante foi Frederick Winslaw Taylor (1856 - 1915) que trazia, juntamente com seus seguidores, a proposta básica de aumento na produçăo pela eficiência do nivel operacional.

"Para tanto, preconizavam a divisão do trabalho, a especialização dos operários e a padronização das atividades e tarefas por eles desenvolvidas. Assim, o operário passava a saber cada vez menos do todo que constituía seu trabalho, para passar a saber cada vez mais a respeito da parte que lhe cabia." (Kurcgant, 1991: 5)

Toda a base científica dessa teoria foi dada através dos estudos de tempo e movimento realizados por Taylor que visavam, basicamente, a padronizaçăo das tarefas, bem como a estipulação do tempo necessário para desenvolvê-las, além de estudos para a adequação do ambiente físico ao trabalho. A supervisão funcional também passa a ter papel primordial na administraçăo científica visto que, com a especialização do operário e a conseqüente perda da visăo do todo, se torna necessário buscar os elos entre as partes e esse todo. Essa tarefa passa a ser feita pelo supervisor que, para a realização dessa função, se vê imbuído da chamada autoridade funcional.

Contemporâneo de Taylor, Henry Fayol (1841 - 1925) cria a Teoria Clássica da Administração, que tem suas premissas básicas calcadas na estrutura administrativa da empresa, onde valoriza, sobremaneira, a autoridade, a responsabilidade, a disciplina, a unidade de comando e de direção e a 
subordinaçăo do interesse particular ao interesse geral da empresa. Sob influência das estruturas eclesiásticas e militares, concebe a organização empresarial como uma estrutura rigidamente hierarquizada, estática e limitada surgindo a divisăo horizontal do trabalho, com agrupamento de atividades afins ou departamentalização. $\mathrm{Na}$ linha vertical da hierarquia, estabelece normas e regras rígidas a serem seguidas pelos administradores e seus subordinados.

Segundo Kurcgant (1991), a amarraçăo da rigidez empresarial que se formou com as duas teorias anteriores, foi completada pelos conhecimentos trazidos por Max Weber (1864 - 1920) dentro da chamada Teoria Burocrática, que enfatizou a racionalidade, ou seja, a adequação dos meios utilizados nas organizaçőes com vistas a atingir os resultados esperados. Sua influência passou a ser sentida mais fortemente a partir de 1940 , com o aumento na complexidade das organizaçōes e a conseqüente necessidade de serem buscadas novas formas de controle de pessoal. Com isso, se detalhou, pormenorizadamente, como as tarefas deveriam ser feitas, o que exigia um treinamento minucioso do operário. Nessa ótica, a impessoalidade nas relaçōes humanas dentro do trabalho é um ponto importante a ser considerado, sendo que o apego às regras, normas e regulamentos passou a dar o tom dessa impessoalidade. Há também uma ênfase muito forte, dada por essa teoria, à autoridade racional-legal, com o estabelecimento de uma rígida hierarquia vertical dentro da instituiçăo.

Com essa visão nova para a organização do trabalho em geral, o hospital passa a ser visto como uma empresa e, como tal, adere fortemente ao modelo funcionalista/burocrático como fulcro orientador do trabalho e do trabalhador que ai atua. Porém, a incorporação desses principios por parte da instituiçăo hospitalar não se deu de forma homogênea, variando de um país a outro e de uma instituição a outra dentro de um mesmo país. Mas, mesmo com essa aderência desigual aos princípios científicos da organização do trabalho, é inconteste que todas as instituições hoje the devem grandes tributos no que se refere à administraçăo e ao desenvolvimento de suas funçőes. Como nos fala Pitta (1989: 40),

"da profana incumbência de sequestrar pobres, moribundos, doentes e vadios do meio social, escondendo o incômodo e disciplinando os corpos e guardandoos até a morte à nobre função de salvar vidas, o hospital tem percorrido um caminho complexo e tortuoso em busca de "tecnologização" científica adequada às suas novas funções."

E com o aumento crescente na complexidade das atividades desenvolvidas dentro do hospital ocorrida nas últimas décadas, houve também necessidade de diversificação dos profissionais que aí atuam, sendo que a chamada "equipe de saúde" já năo está mais centrada apenas na figura do médico e dos membros da equipe de enfermagem, principalmente da atendente de enfermagem. As especializaçőes e subespecializaçőes se fazem a perder de vista, especialmente 
nas grandes instituiçōes, tendo atingido as culminâncias de profissionais médicos especialistas no diagnóstico e tratamento de uma determinada doença. Dessa forma, vários outros profissionais passam a fazer parte do cenário hospitalar, tais como a enfermeira, a nutricionista, a assistente social, o psicólogo, o fisioterapeuta, o farmacêutico, o bioquímico, etc, além de diversos ocupacionais.

Acompanhando o crescimento e especialização da área clínica do hospital, houve também um grande incremento na área administrativa. Assim, a preocupação com custos, contenção de despesas, pagamentos, controle de material, equipamentos e pessoal ganha uma grande importância dentro desse sistema complexo, sendo que essa instituição adquire, definitivamente, as feições de uma "empresa da saúde" que, de forma paradoxal, trabalha eminentemente com a cura da doença. Também nesse setor acontece uma grande diversificação de atividades trazendo consigo uma marcante estruturação burocrática.

A enfermagem, como parte integrante dessa instituição, também sofreu o mesmo processo de aumento na complexidade de suas atividades e conseqüente diversificação dos seus executores em várias categorias. Com o incremento na demanda das necessidades de saúde da população, bem como o fortalecimento do conhecimento científico nessa área, as especializaçōes também passam a fazer parte da formação das trabalhadoras da área da enfermagem, principalmente da enfermeira, sendo que esta profissional passa a liderar a denominada "equipe de enfermagem". A estrutura de trabalho dessa equipe, a exemplo dos demais setores das instituições de saúde, passa a se desenvolver dentro dos chamados moldes funcionalistas.

Vários autores têm se dedicado ao estudo das influências das diversas teorias da administração na organizaçăo do trabalho da enfermagem. As críticas nesse sentido têm sido bastante contundentes, principalmente no que se refere à utilizaçăo do método funcional no desenvolvimento e distribuição das atividades entre os diversos membros da equipe de enfermagem. Lambertsen (1962) já se referia à inadequaçăo desse método dizendo que,

"usando o método funcional, a enfermeira diplomada tende a perder contato com os pacientes. Ela se preocupa principalmente com as medicações $e$ tratamentos ou apenas com os doentes mais graves. Este método pode resultar em trabalho tipo produção em massa, com a identidade do paciente perdida na lista de obrigações a serem cumpridas".

Esse método prevê a distribuição das atividades, na qual se busca compatibilizar a complexidade das mesmas com o grau de preparo de quem as executará. Desse modo, as atividades mais simples, tais como organização e limpeza de materiais, higiene dos pacientes, etc, ficam a cargo dos atendentes de enfermagem; os curativos, medicaçōes, cuidados com sondas, infusōes venosas, verificaçăo de sinais vitais, etc, são desenvolvidos pelos auxiliares e técnicos de 
enfermagem. À enfermeira compete, além de todas essas atividades, aquelas que Ihe são privativas, quais sejam, as sondagens e o cuidado ao paciente em estado grave, bem como o planejamento, coordenação e avaliação da assistência de enfermagem, quer na unidade de internaçăo, quer no âmbito mais geral do serviço de enfermagem.

O respaldo burocrático a essa modalidade de trabalho é dado pela formalizaçăo de normas e rotinas institucionais que, segundo Massarollo in Kurcgant, 1991,

"representam a tentativa deliberada de estabelecer relações entre os componentes que deverão alcançar os objetivos propostos. Determina quem faz o que e onde nas organizações, assim como evidencia as relações de autoridade $e$ poder existente entre os componentes organizacionais. $\hat{E}$ um dos meios de que se utilizam as organizaçōes para atingirem eficientemente seus objetivos".

Assim, vemos que a noção empresarial fortemente arraigada às instituiçöes de saúde e, particularmente, ao hospital, busca o aumento da produtividade e do lucro, a economia (de tempo, espaço, energia, movimentos, sentimentos e dinheiro), a racionalidade na aplicaçăo dos recursos (financeiros, materiais e humanos), sendo que esse passa a ser o discurso presente no dia-a-dia dos administradores dessas instituições. $E$ os manuais, as normas, rotinas e regulamentos passam a ditar o comportamento das pessoas, determinando quando, como e onde as coisas devem ser feitas, bem como buscando doutrinar - sentimento de seus executantes. A hierarquia rígida procura tolher a espontaneidade das relaçōes entre as pessoas, subjugando-as ao mando.

A enfermeira, tendo sua formação profissional intimamente ligada ao hospital, particularmente a hospitais universitários cuja característica própria já faz com que adiram mais fortemente aos métodos funcionalista/burocráticos de trabalho, passa a incorporar esses conceitos e a utilizá-los em sua prática diária. Essa situação é especialmente reforçada pelo fato de ser a enfermeira considerada a "líder nata" da equipe de enfermagem e, como tal, fica a seu encargo todo o planejamento e coordenação do trabalho dos demais membros dessa equipe.

A formação teórica para o desempenho dessa liderança se faz, na maioria das vezes, dentro dos moldes tradicionalistas da administração, onde são resgatados, principalmente, os conceitos dos seus precursores e que ainda permanecem presos ao "quem faz o que e como". Como nos coloca Rozendo (1995: 18),

"parece-me que a questão da liderança na enfermagem, surge então como uma condição a priori em que os enfermeiros, independentemente de sua experiência anterior, já mergulham no mercado de trabalho sob este estado, com a responsabilidade de "liderar" a equipe de enfermagem, num clima de grandes expectativas. Creio que seja uma missão extremamente espinhosa, 
pois o que se espera, incluindo a expectativa dos próprios enfermeiros é que eles respondam a esse anseio, sem que tenham sido preparados para isso. Neste bojo de expectativas, não raro se desenvolvem sentimentos de frustração, tanto por parte dos profissionais inseridos no mercado de trabalho, que não conseguiram dar conta do recado quanto dos orgãos formadores, pelo mesmo motivo."

Essa angústia, gerada pelo confronto entre o idealizado, o aprendido e o possível, o real, o vivido, traz em si grande parte da insatisfação das enfermeiras quando adentram no "mercado de trabalho", pois sentem toda a frustração ante a impossibilidade de "controlar o que não se presta ao controle".

Longe de tentar compreender as particularidades próprias do hospital, enquanto local onde se trabalha com o limite humano, representado pela dor e sofrimento, vida e morte, a formação profissional da enfermeira, bem como dos demais membros da equipe de saúde, reforça o sistema de trabalho em "linha de montagem", como se o produto final do trabalho ai desenvolvido fosse sempre uma bem acabada peça da engrenagem maior que é a sociedade. "Produto e produtor" passam pela mesma "coisificação" que desconsidera a dimensão humana, a subjetividade, com toda a carga de contradição que ela traz e que năo se presta à "pasteurização" de normas e regras que ditam "o como fazer e o que sentir".

O grupo de enfermagem é quem mais agudamente sofre esse processo de massificação, pois tem todos os seus fazeres rigorosamente escrutinados em passos minuciosos, com horários rígidos, impostos sob a benemérita face do "tudo fazer pelo bem do doente". E dentro desse "processo industrial de produção da saúde", há uma escala mensal a cumprir, uma carga horária a acatar, uma escala de tarefas a seguir, uma prescrição a respeitar, um procedimento técnico com seus infinitos passos a executar, uma hierarquia a obedecer, um paciente indisciplinado a suportar. Tudo minuciosamente esperado e controlado para que não haja emperramentos na máquina, da qual fazem parte pacientes e profissionais da saúde. Rezende (1991:87) resume esse estado de coisas colocando que

\footnotetext{
"trabalho, disciplina, previsão, finalidade. Com que intensidade tais atributos foram embutidos em nossa formação profissional e, posteriormente, reproduzidos por nós? São mesmo modelares do comportamento esperado de um profissional de saúde. Demarcam seriedade, circunspeção e também sisudez. De tão enfatizados e potencializados nos prenderam numa armadilha que nós mesmos urdimos. Protegidos no estereótipo demonstramos uma imagem de competência, que deixa fora de suas fronteiras toda alegria espontânea e sem objetivo, que se esgota no próprio ato de se alegrar."
} 


\section{HOSPITAL - LUGAR DE VIDA}

Mas, permeando esse espaço rígida e racionalmente instituído, temos a dimensão do vivido que busca romper com o "ser humano-máquina" e resgatar o "ser humano-humano", com sua escandalosa incoerência, que tem no viver coletivo, no grupo, o substrato propício para se manifestar. Pois, como ainda nos afirma Rezende (1991: 39),

"(...) é importante que mesmo o local finalista de trabalho assegure o estarjunto, até porque os próprios trabalhadores encarregam-se de, para tornar suportável a rotina do dever-ser, fazer do "locus tecnicus" também o local da piada, do "corpo mole", da "paquera", da maledicência, da confidência, dos planos e das fantasias."

Assim, surge o que a autora chama de "respiradouros sociais", que capilarizam essa ordem rigidamente estabelecida e que é enfrentada, de forma indireta, através de silêncios, de simulacros, do jogo duplo, da astúcia, da teatralidade e da inserção do lúdico em suas diversas formas. $E$ em lugar da solidariedade mecânica, contratual, hierarquizada, institucional, contrapõe-se a solidariedade orgânica (Maffesoli, 1985) ${ }^{4}$, que busca o resgate da noção de "grupo" 5 (em oposição ao conceito de "equipe"), (re)descobrindo a humanização do ambiente hospitalar, de forma a torná-lo o mais 'vivivel' possivel.

A solidariedade orgânica presente nas relaçöes entre os diversos membros da "equipe/grupo de saúdem" 6 , tem seu cimento agregador no afetual, no ombro a

${ }^{4}$ MAFFESOLI explicita a solidariedade mecânica como aquela em que a solidariedade não se manifesta diretamente ao outro, mas está sempre mediada por uma estrutura tal como o partido, a igreja, o clube, o sindicato, etc. e tem um caráter eminentemente finalista. Ả ela o autor contrapõe a noção de solidariedade orgânica ou eletiva, que nos fala de uma escolha por afinidades mais do que por objetivos a serem atingidos, pelo simples "estar junto à toa", regida pelo sentimento de atraçăo-repulsa. (MAFFESOLI,M. A sombra de Dionísio. Rio de Janeiro: Graal, 1985.)

5 Pela conotaçăo mais "afetual", mais "vitalista" que a noçăo de grupo nos dá, nós a preferimos em lugar do termo equipe, que traz consigo uma conotação mais energetista, funcionalista. Assim, em lugar de "equipe de enfermagem", utilizaremos, doravante, a denominação "grupo de enfermagem", posto que estamos trabalhando com a dimensão relacional desse grupo.

${ }^{6} \mathrm{~A}$ dualidade aqui mantida na utilização do termo "equipe/grupo de saúde" se deve ao fato que, embora possamos dizer que a socialidade também esteja presente dentro desse grupo maior de profissionais atuantes no hospital, haveria a necessidade de estudo específico sobre o mesmo, explicitando suas características inerentes, como procuramos fazer aqui com o grupo de enfermagem. Assim, manteremos a denominaçăo corrente de "equipe de saúde" quando nos referirmos a todos os profissionais da área que atuam dentro do hospital, diferenciando-o do "grupo de enfermagem", alvo do nosso estudo. 
ombro. Porém, longe de ser um grupo unificado, ele se apresenta conflitual sob muitos aspectos. E dentro dessa visăo caleidoscópica, a diferença (de profissões, de interesses, de poderes, de atitudes, de sentimentos e de sonhos) que o hospital abriga em nada pode representar uma globalidade abstrata e homogênea. A socialidade fragmentada e totalmente plural que aí se instala traz consigo a

"harmonia diferencial" $e$, dentro dela "o jogo da diferença permite a neutralização dos poderes, levando-os a uma confrontação $e$, assim, relativizando-os"

(Maffesoli, 1984). Porém, essa confrontaçăo com o poder (em qualquer uma das suas muitas manifestaçōes) raramente se dá de forma frontal, mas sim dissimuladamente, através de simulacros, de astúcias, de jogo duplo, de abstençăo e de silêncios.

Nesse espaço/tempo quotidiano institucional, a potência, mais que o poder, atua de forma a "harmonizar" (conflitualmente) os interesses diversos pois, aparentemente aceitando os valores externamente estabelecidos, isto é, não se lutando diretamente contra eles, ganha-se distância ao mesmo tempo em que se zomba deles. Porém, essa potência não se mostra às claras, ela se "dilui" no todo social, e é isso que confere a sua permanência e eficácia. Pois, como Maffesoli (1984) nos coloca,

“(...) não há adesão nem constatação que sejam sentidos como dois polos complementares de um mesmo interesse. Basta desmitificar com um sorriso, com um gracejo, com uma simples palavra bem sentida (...) Esta atitude é altamente subversiva na medida em que (...) existe uma presença mas não uma participação, o jogo é perfeito e o resultado eficáz. Neste sentido, o cinismo é uma técnica de defesa incomparável".

Dessa forma, a expansão individual só é garantida no coletivo e é essa expansăo que dá alento ao bem-estar comum. E é dentro desse "todo confusional" que o hospital representa, visto que os interesses dos que aí atuam se mesclam de tal forma que acaba por haver "a dissolução do indivíduo e do social no todo ou, em outras palavras, a perda gradual do individuo no coletivo" (Teixeira, 1988:183), que as "pessoas" (não os trabalhadores ou "funcionários") agem e reagem intersubjetivamente, dentro de uma ética grupal própria ( $e$ năo de uma "moral" prosaíca). E é essa dimensăo humana, que envolve relaçőes afetuais muito mais do que as propaladas relaçőes profissionais, que passa a imprimir seu tom ao conjunto dentro dessa instituiçăo que se pretende finalista e racionalizadora. E não poderia ser de outra forma, senão como buscar encantamento num mundo marcado, principalmente, pela dor, sofrimento e morte? Como fazer do hospital um espaço onde subsista a alegria, o lúdico, o 
prazer? De onde retirar o húmus fértil que dá sustentação a esse "querer viver" que, freqüentemente, contraria todo o instituido? Pois, como Pitta (1989:19) nos fala quanto ao trabalho dentro do hospital,

"esse contato constante com pessoas fisicamente doentes ou lesadas, com freqüência adoecidas gravemente, impõe um fluxo contínuo de atividades que envolvem a execução de tarefas agradáveis ou não, repulsivas $e$ aterrorizadoras muitas vezes, que requerem...um exercício cotidiano de ajustes $e$ adequações de estratégias defensivas para o desempenho das tarefas."

Assim, as estratégias de sobrevivência diária, que procuram, principalmente, transformar o trabalho penoso dentro do hospital em fonte não só de sofrimento mas também de prazer, têm por base a relativização do fortemente instituído, tornando-o "vivivel". Isso transforma o trabalho ai desenvolvido em uma via de mão dupla pois, ao mesmo tempo que representa sofrimento e dor no enfrentamento do limite do ser humano trazido pela figura da morte, ele também é prazer, transmutado em troca simbólica. Nesta troca, o dom, aqui representado pelo oferecimento do trabalho, o sofrimento sentido pelo e com o outro, as angústias, ansiedade, "stress", etc, é recompensado pelo contradom, advindo do compartilhar sentimentos, situações, espaço, enfim, pelo viver coletivo. E o grupo de enfermagem, mais do que qualquer outro, vive e sobrevive nesse e desse trabalho quotidiano.

Não menos presente e atuante nesse cenário e, por passar grande parte do seu dia dentro do ambiente hospitalar, a enfermeira se apega afetualmente a esse "território" que poderíamos representar pela figura da domus ${ }^{7}$ (Bachelard, 1993: 36), sendo que deposita ai seus sonhos e práticas quotidianas, fazendo desse húmus um fator de socialidade junto a toda equipe de saúde. Há, por parte da profisssional, um forte sentimento de pertença ao ambiente de trabalho que, somado ao seu envolvimento afetual com as pessoas que compartilham o mesmo espaço, principalmente os demais membros do grupo de enfermagem e pacientes, faz com que ela não permaneça indiferente aos muitos problemas que afetam, sobremaneira, a assistência de enfermagem, buscando resolvê-los da melhor maneira possivel. $E$ por haver essa estreita proximidade entre a enfermeira e demais membros da equipe de saúde, acreditamos que essa profissional seja a grande engendradora da "teia afetual" que envolve os diversos serviços do hospital, visto ter seu trabalho imbricação com todos eles.

\footnotetext{
${ }^{7}$ Palavra latina que designa a casa com toda a sua carga afetiva e que, como nos coloca BACHELARD, "é um corpo de imagens que dão ao homem razões ou ilusões de estabilidade".
} 


\section{O OLHAR CALEIDOSCÓPICO}

Porém, se esse atuar relacional já faz parte do trabalho quotidiano dessa profissional, é ainda tênue a compreensão de que toda vivência coletiva, longe de ser pacifica, tem no conflitual e na diferença a sua tônica. $E$ isso tem gerado na enfermeira um forte sentimento de inadequação e angústia diante da falsa crença de que, sendo a "lider natural" do grupo de enfermagem, possa "controlar" a dinâmica da assistência ao paciente, mesmo com todas as movências e mutabilidade que ela traz. Ainda the escapa a plena percepção de que o ambiente "confusional" do hospital, na diversidade de interesses e sentimentos que traz, não se presta à homogeneização que se pretende quando the colocamos as amarras fortemente atadas do instituido. Assim, palavras como controle, organização e planejamento precisam ser relativizadas pela compreensão do vivido que ai se instala e que, sendo de outra ordem, traz consigo sentimentos e emoções até então pouco considerados dentro das linhas administrativas adotadas pelas instituiçōes de saúde e, conseqüentemente, pela enfermagem. No interior dessa nova visão, as noçőes de grupo, de viver coletivo, do prazer do estar junto, do jogo da diferença precisam ser considerados enquanto formas engendradoras da socialidade que se configura dentro do hospital, abandonandose a idéia do ambiente asséptico, principalmente no que diz respeito às relações afetuais ai existentes.

Da compreensão, por parte da enfermeira, quanto a esses aspectos do quotidiano hospitalar resultará uma menor ansiedade pela busca por uma "pasteurização" de comportamentos e conhecimentos, que começa a ser construída ainda na sua formação e que parecem perpetuar-se durante a sua atuação profissional. Também acreditamos que o processo de formação profissional da enfermeira precisaria redirecionar seu foco para as visões teóricas que surgem trazendo em seu bojo a valorização da relacionalidade, da afetividade, da humanidade dentro do espaço/tempo do trabalho, bem como a movência do quotidiano e a especificidade de cada ambiente. É necessário considerar também que, se alguma "ordenação" deve ser dada à esse "todo confusional" reinante no hospital, ela precisa ultrapassar a monovalência racionalista, resgatando o vitalismo ai presente, pois o que essas profissionais da dor buscam é

"harmonizar, através de um ritmo específico, o tempo desumano das cadências impostas e do tédio programado, readquirir, à revelia do olhar dominante, momentos da própria existência e, assim, salvaguardar o equilibrio físico e psicológico, gravemente ameaçado"(Morin, Baudrillard, Maffesoli, 1993: 65) ${ }^{8}$.

${ }^{8}$ MAFFESOLI,M. Liberdades intersticiais. In: MORIN,E., BAUDRILLARD.J., MAFFESOLI. M. A decadência do futuro e a construção do presente. Florianópolis: Editora da UFSC, 1993. p.65. 


\section{BIBLIOGRAFIA}

1. BACHELARD,G. A poética do espaço. Săo Paulo: Martins Fontes, 1993.

2. FOUCAULT,M. Microfísica do poder. $11^{\text {a }}$ ed. Rio de Janeiro: Graal, 1993.

3. KURCGANT,P. (Org.) Administração em enfermagem. Săo Paulo: EPU, 1991.

4. LAMBERTSEN,E.C. Equipe de enfermagem - organizaçăo e funcionamento. Rio de Janeiro: ABEn/SESP, 1962.

5. MAFFESOLI,M. A sombra de Dionísio. Rio de Janeiro: Graal, 1985.

6. A conquista do presente. Rio de Janeiro: Rocco, 1984.

7. MORIN,E., BAUDRILLARD.J., MAFFESOLI.M. A decadência do futuro e a construçāo do presente. Florianópolis: Editora da UFSC, 1993.

8. PITTA,A.M.F. Trabalho hospitalar e sofrimento psíquico. São Paulo: Departamento de Medicina Preventiva, 1989. 214p. Tese (Doutorado) Universidade de São Paulo.

10. REZENDE,A.L.M.de. A sedução dos mitos da saúde/doença na telenovela. Săo Paulo: Faculdade de Educaçăo, 1991. 287p. Tese (Doutorado) - Universidade de Săo Paulo.

11. ROZENDO,C.M. Liderança na enfermagem: refletindo sobre um mito. Ribeirão Preto: Escola de Enfermagem de Ribeirăo Preto, 1995. 156p. Dissertaçăo (Mestrado) - Universidade de Săo Paulo.

12. TEIXEIRA,M.C.S. Sócio-Antropologia do cotidiano e educaçāo: repensando aspectos da gestão escolar. São Paulo: Faculdade de Educação, 1988. 303p. Tese (Doutorado) - Universidade de São Paulo.

13. TREVIZAN,M.A. A função administrativa da enfermeira de instituição hospitalar burocratizada. Ribeirăo Preto: Escola de Enfermagem de Ribeirão Preto, 1986. 200p. Tese (Doutorado) - Universidade de São Paulo. 